\title{
Single cell infection with influenza A virus using drop-based microfluidics
}

3 Emma Kate Loveday ${ }^{\mathrm{a}}$, Humberto S. Sanchez ${ }^{\mathrm{a}}$, Mallory M. Thomas ${ }^{\mathrm{a}}$, Connie B. Changa ${ }^{\mathrm{a}}$

$4 \quad{ }^{a}$ Center for Biofilm Engineering, Department of Chemical and Biological Engineering, Montana

5 State University, Bozeman MT 59717

6 - Corresponding author: connie.chang@montana.edu

7 ORCID

8 Emma Kate Loveday 0000-0002-1154-7728, emma.loveday@montana.edu

9 Humberto S. Sanchez 0000-0003-3298-6348, humberto.sanchez@montana.edu

10 Mallory Thomas 0000-0001-7218-2868, mallory.thomas1@student.montana.edu

11 Connie B. Chang 0000-0001-9555-8223, connie.chang@montana.edu

\section{Summary:}

14 Influenza A virus (IAV) is an RNA virus with high genetic diversity which necessitates the

15 development of new vaccines targeting emerging mutations each year. As IAV exists in

16 genetically heterogeneous populations, current studies focus on understanding population

17 dynamics at the single cell level. These studies include novel methodology that can be used for

18 probing populations at the single cell level, such as single cell sequencing and microfluidics.

19 Here, we introduce a drop-based microfluidics method to study IAV infection at a single cell

20 level by isolating infected host cells in microscale drops. Single human alveolar basal epithelial

21 (A549), Madin-Darby Canine Kidney cells (MDCK) and MDCK + human siat7e gene (Siat7e)

22 cells infected with the pandemic A/California/07/2009 (H1N1) strain were encapsulated within

$2350 \mu \mathrm{m}$ radii drops and incubated at $37^{\circ} \mathrm{C}$. We demonstrate that drops remain stable over 24

24 hours, that $75 \%$ of cells remain viable, and that IAV virus can propagate within the drops. Drop-

25 based microfluidics therefore enables single cell analysis of viral populations produced from

26 individually infected cells.

28 Keywords (3-6 words):

29 Drop-based microfluidics, influenza, single cell, droplets 


\section{Introduction}

Single-cell studies of viral infections enable high-resolution examination of

34 heterogeneous virus populations. Differential selective pressures in both the host cell and virus

35 population lead to variability in virus replication and production that enables antiviral escape,

36 zoonotic spillover events, and changes in virulence or pathogenesis (Dolan, Whitfield, and

37 Andino, 2018). Influenza A virus (IAV) is a negative-strand RNA virus with populations

38 containing high genetic diversity due to its segmented genome, rapid replication rate, and low

39 fidelity RNA-dependent RNA polymerase (RdRp) (Dolan et al., 2018). As such, IAV infection

40 results in a diverse swarm of unique variants exhibiting heterogeneous genotypes and phenotypes

41 (Brooke, 2017; Petrova and Russell, 2018).

Heterogeneous IAV populations can be examined using methods that capture diversity at

43 the single cell level. Such methods include microfluidic techniques to perform single cell

44 transcriptomics (Russell et al., 2019; Russell, Trapnell, and Bloom, 2018; Sun et al., 2020) or

45 isolation of cells using limiting dilutions in well plates (Heldt et al., 2015; Kupke et al., 2020).

46 These studies have identified large variations in total viral mRNA expressed, infectious virus

47 produced, and host transcriptional response to infection. However, isolating single cells using

48 limiting dilutions can limit analysis to only a few hundred cells (Heldt et al., 2015; Kupke et al.,

49 2020; Russell et al., 2019; Russell et al., 2018; Sun et al., 2020).

A promising method to study single cell infection at high-throughput is drop-based microfluidics, which offers the ability to compartmentalize and rapidly assay individual cells (Matuła, Rivello, and Huck, 2020; Mazutis et al., 2013; Prakadan, Shalek, and Weitz, 2017; Xu et al., 2020; Zilionis et al., 2017). A drop-making microfluidic device is used to create microscale aqueous drops that are surrounded by an immiscible oil and stabilized with a biocompatible surfactant (Holtze et al., 2008). Compared to larger scale in vitro culturing methods where cells are grown in flasks or well plates, drop-based microfluidics creates millions of discrete bioreactors that house single cells in which viruses can replicate (Fischer et al., 2015; Tao et al.,

58 2015a). This allows for viral replication events to be analyzed independently within these droplet

59 bioreactors. Drop-based microfluidics has recently been applied to study infectivity (Fischer et

60 al., 2015; Tao et al., 2015a) and recombination (Tao et al., 2015b) of the non-enveloped,

61 positive-sense murine norovirus (MNV-1) (Henderson, 2008). Expanding the applicability of 
62 drop-based microfluidics to other viruses, such as enveloped viruses that require a broad range of

63 host cells, would greatly increase capacity for single cell virology studies.

64 In this work, drop-based microfluidics was applied towards culturing and quantifying

65 IAV replication at the single cell level. Three different cell lines, alveolar basal epithelial (A549)

66 cells, Madin-Darby Canine Kidney (MDCK) cells and MDCK + human siat7e gene (Siat7e)

67 cells (Chu et al., 2009; Chu et al., 2010), were tested for their viability and ability to support IAV

68 infection in drops compared to bulk tissue culture. Initial one step growth curves in all three cell

69 lines were performed with the A/California/07/2009 H1N1 IAV strain. Both A549 and MDCK

70 cells supported high levels of RNA replication while the Siat7e cells had a stagnant level of viral

71 RNA present over 48 hours (h). Drop stability, cell loading, and viability was tested within 100

$72 \mu \mathrm{m}$ diameter drops and quantified after $24 \mathrm{~h}$ of incubation, a sufficient amount of time for one

73 productive round of IAV infection. The drop radii $(R)$ between 0 and $24 \mathrm{~h}$ for all three cell lines

74 differed by less than $1.6 \mu \mathrm{m}$ after incubation demonstrating consistent drop stability. Cell

75 loading, or the number of cells loaded within drops, was quantified and compared using two

76 methods of imaging: a high-speed camera and still images of drops on a hemocytometer. The

77 two methods of measuring cell loading were determined to be incomparable using a mixed

78 effects Poisson model. Quantification of cell loading from the still images was closest to the

79 estimated Poisson loading model for all three cell lines, suggesting its usage as a more reliable

80 method for measuring cell loading compared to the high-speed camera. All cell lines were found

81 to have a minimum mean of at least $75 \%$ viability with no significant difference between

82 adherent and non-adherent cell types. The cells were infected with A/California/07/2009 H1N1

83 at an MOI of 0.1 to compare virus production over time between cells infected on standard tissue

84 culture plates and cells infected and encapsulated as single cells in drops. Viral replication and

85 production was quantified using reverse transcription quantitative polymerase chain reaction

86 (RT-qPCR) and plaque assays. For both A549 and MDCK cells, the increase in detectable viral

87 RNA as measured by RT-qPCR, from 0 to $24 \mathrm{~h}$ was similar for both drop and bulk infections.

88 Similar results were observed for measurements of infectious virus produced for both drop and

89 bulk infections of MDCK and A549 as measured by plaque assays. Our findings demonstrate

90 that standard adherent cell lines for propagating and studying IAV can be used in drops, thereby

91 expanding the capabilities to study virus infection at a single cell level, which until recently has 
92 only been demonstrated for non-adherent, spinner-adapted host cells (Fischer et al., 2015; Tao et

93 al., 2015a; Tao et al., 2015b).

94 The drop-based microfluidic methods developed in this work will enable future studies of

95 single cell IAV infections using multiple cell lines. The methods expand the application of drop-

96 based microfluidics from the non-enveloped, positive-sense MNV-1(Fischer et al., 2015; Tao et

97 al., 2015a; Tao et al., 2015b) to include the enveloped and negative-sense IAV, thus broadening

98 the scope of single cell virology assays. Additionally, this work can serve as a blueprint for

99 testing, comparing and implementing drop-based microfluidics methods in future single cell

100 studies. With the recent interest and development of single cell -omic technologies for studying

101 viral infections (Combe et al., 2015; Cristinelli and Ciuffi, 2018; Drayman et al., 2019; Gérard et

102 al., 2020; Guo et al., 2017; Kupke et al., 2020; Liao et al., 2020; Lin et al., 2019; Sen et al., 2012;

103 Timm, Warrick, and Yin, 2017; Zanini et al., 2018), we expect this work to further expand

104 capabilities and increase applications of single cell technologies in virology.

2. Material and Methods

$107 \quad 2.1$ Cells and viruses

108 Human alveolar epithelial cells (A549), Madin-Darby Canine Kidney cells (MDCK) and MDCK

109 + human siat7e gene (Siat7e) cells were obtained from ATCC (CCL-185, CCL-34) and Dr.

110 Joseph Shiloach (NIH), respectively (Chu et al., 2009; Chu et al., 2010). A549 cells were

111 propagated in Hams F-12 (Corning) media supplemented with 10\% fetal bovine serum

112 (HyClone) and 1X Penicillin/Streptomycin (Fisher Scientific). MDCK and Siat7e cells were

113 propagated in DMEM (Corning) media supplemented with 10\% fetal bovine serum (HyClone)

114 and 1X Penicillin/Streptomycin (Fisher Scientific). The IAV virus strain A/California/07/2009

115 (H1N1) was obtained from Dr. Chris Brooke (UIUC). Stocks of A/California/07/2009 were

116 propagated and titered on MDCK cells.

\section{$118 \quad 2.2$ Microfluidic device fabrication}

119 Microfluidic devices for drop making were fabricated by patterning SU-8 photoresist

120 (Microchem SU-8 50) on silicon wafers (University Wafer, ID\# 447, test grade) to create $100 \mu \mathrm{m}$

121 tall and $100 \mu \mathrm{m}$ wide channels. Polydimethylsiloxane (PDMS) (Sylgard 184) was poured onto

122 the wafers at a 10:1 mass ratio of polymer to cross-linking agent according to standard 
123 photolithography techniques (Duffy et al., 1998). Air was purged from the uncured PDMS by

124 placing the filled mold in a vacuum chamber for at least $1 \mathrm{~h}$. The PDMS was cured in an oven at $12555^{\circ} \mathrm{C}$ for $24 \mathrm{~h}$ and ports were punched into the PDMS slab with a $0.75 \mathrm{~mm}$ ID diameter biopsy

126 punch (EMS Rapid-Core, Electron Microscopy Sciences). The PDMS slab was bonded to a 2-in

127 by 3-in glass slide (VWR micro slides, cat. \#48382-179) after plasma treatment (Harrick Plasma

128 PDC-001) for $60 \mathrm{~s}$ at high power $(30 \mathrm{~W})$ and $700 \mathrm{mTorr}$ oxygen pressure. The drop making

129 devices were made hydrophobic by flowing Aquapel (Pittsburgh Glass Works) through the

130 channels, followed by blowing the channels with air filtered through a GVS ABLUO ${ }^{\text {TM }} 25 \mathrm{~mm}$

$1310.2-\mu \mathrm{m}$ filter (Fisher Scientific) before baking the devices in an oven at $55{ }^{\circ} \mathrm{C}$ for $1 \mathrm{~h}$.

\subsection{Cell encapsulation in drops}

134 Cells were seeded on to T25 flasks or 6-well plates at a density of $1 \times 10^{5}$ cells $/ \mathrm{cm}^{2}$ and

135 incubated overnight. Cells were prepared for encapsulation by washing $2 \times$ with PBS followed by

136 trypsinization to remove cells from the surface of the flasks or plates. The appropriate culture

137 media containing 10\% FBS was added to the cells to neutralize trypsinization and cells were

138 collected and centrifuged at $500 \times \mathrm{g}$ for 5 minutes. The cell pellet was gently washed with 3-5

$139 \mathrm{~mL}$ of PBS and centrifuged a second time at $500 \times \mathrm{g}$ for 5 minutes. The cell pellet was gently

140 resuspended in FBS-free media to reach $2 \times 10^{6}$ cells $/ \mathrm{mL}$ in their designated media. $10 \mu \mathrm{L}$ of

141 cells were placed on a hemocytometer to visualize and confirm cell concentration and verify the

142 presence of mostly single cells. Cells were loaded into a $3 \mathrm{~mL}$ syringe (BD) for injection onto a

143 flow-focusing microfluidic device for encapsulation into $100 \mu \mathrm{m}$ drops ( 523 pL) (Anna,

144 Bontoux, and Stone, 2003). Drops are stabilized in a fluorinated HFE7500 oil (3 M) continuous

145 phase with a $1.5 \% \mathrm{w} / \mathrm{w}$ solution of PEG-PFPE 2 -based surfactant (RAN Biotechnologies, 008-

146 FluoroSurfactant). The fluids were transferred into the microfluidic device with syringe pumps

147 (New Era NE-1000) controlled by a custom LabVIEW (2015) program at flow rates of 1000

$148 \mu \mathrm{L} / \mathrm{h}$ the aqueous phase and $3000 \mu \mathrm{L} / \mathrm{h}$ for the oil phase. A 1,500 $\mu \mathrm{L}$ total volume consisting of

$149375 \mu \mathrm{L}$ of drops containing cells and $1,125 \mu \mathrm{L}$ of oil, was collected in a $2 \mathrm{~mL}$ microcentrifuge

150 tube (Eppendorf). Following encapsulation, drops containing cells were incubated in an open

151 microcentrifuge tube covered with parafilm at $37{ }^{\circ} \mathrm{C}$ with $95 \%$ relative humidity and $5 \% \mathrm{CO}_{2}$

152 (Fischer et al., 2015). Cells were released from drops by removing the majority of the oil phase

153 and adding $1 \mathrm{~mL}$ of a 20\% w/w 1H,1H,2H,2H-Perfluoro-1-octanol (PFO) in HFE7500 oil to 
154 break the emulsion followed by vortexing. Centrifugation at $500 \times \mathrm{g}$ for five minutes was used to

155 separate the aqueous cell suspension from the oil phase, to isolate cells for further analysis.

\subsection{Drop measurements}

158 Drop radii were measured after imaging a drop monolayer on a hemocytometer with a CCD 159 camera (FLIR Grasshopper3) on an inverted microscope (Nikon Ti-U). The drops were added to

160 a hemocytometer at a density where they are arranged in a monolayer with minimal packing. The

161 minimal packing allows the drops to relax in a spherical shape for better image analysis. A

162 custom MATLAB script was used to determine the radii, $R$, at $0 \mathrm{~h}$ and $24 \mathrm{~h}$ after the cells were

163 incubated. Six images of drops, with a minimum of 300 drops per image per time point, were

164 analyzed. The $R$ for all three cell lines before and after incubation. The drop radii data contains

165 values from multiple timepoints post encapsulation, different cell lines, and multiple

166 experimental dates. A linear mixed effects model, with the experimental date as a random factor,

167 was used to analyze the contributions of cell type and timepoint to the data set.

\subsection{Cell loading and viability}

170 Two methods were used to quantify cell loading in drops. The distribution of cells/drop was

171 determined using still images of a drop monolayer on a hemocytometer as described in 2.4 and

172 footage of the drop formation junction using a high-speed camera (VEO 710L, Phantom). Two

173 high speed videos of the flow focusing junction were recorded at 6,000 frames per second (fps)

174 to capture the formation of individual drops over the course of several frames, with an average of

175505 drops counted from each recording. A Poisson model, with cell lines as the mixed effects,

176 the date as the random effect, and the measurement method as a two-way interaction was applied

177 to determine if the cell encapsulation distributions were a function of the cell line or

178 measurement used. An adjusted p-value was then determined using a multiple comparison across

179 the cell lines and measurement methods. Following encapsulation, drops were incubated at $37^{\circ} \mathrm{C}$

180 with $95 \%$ relative humidity and $5 \% \mathrm{CO}_{2}$. Cells were released from drops as previously

181 described. The cells in the aqueous phase were collected and pelleted at $1500 \times \mathrm{g}$ for five

182 minutes. The cell pellet was resuspended in $200 \mu \mathrm{L}$ PBS. Cells were diluted 1:5 in PBS + 10\%

183 trypan blue stain for a final volume of $50 \mu \mathrm{L}$ to determine cell viability. An unpaired t-test was

184 used to determine if cell viability was significantly different between the cell lines. 


\subsection{IAV infection of adherent cells (A549 and MDCK)}

187 Cells were seeded onto a 6-well plate at a concentration of $1 \times 10^{6}$ cells/well and infected with

188 IAV H1N1 at an MOI of 0.1 in infection media. The infection media consisted of Hams F-12 or 189 DMEM supplemented with 1 mM HEPES (HyClone), 1X Penicillin/Streptomycin (Fisher

190 Scientific), 0.1\% Bovine Serum Albumin (BSA) (MP Biomedical) and $1 \mu \mathrm{g} / \mathrm{ml}$ of TPCK

191 (tolylsulfonyl phenylalanyl chloromethyl ketone)-trypsin (Worthington Biomedical) (Weingartl

192 et al., 2010). Briefly, cells were washed with 1X Phosphate Buffered Saline (PBS) (Corning) and

193 incubated with $200 \mu \mathrm{L}$ of virus inoculum for $1 \mathrm{~h}$. The inoculum was removed and replaced with

$1941.5 \mathrm{~mL}$ fresh infection media for another $1 \mathrm{~h}$ incubation. Infection media was removed, cells

195 were washed with PBS, and the infected cells were detached from the plate by trypsinization.

196 Infected cells were processed as described in 2.3 and resuspended in encapsulation media

197 containing either Hams F-12 or DMEM and 1 mM HEPES, 1X Penicillin/Streptomycin, and

198 0.1\% BSA (MP Biomedical). The infected cell suspension was split into two populations with 199 one population replated as a bulk control and the other encapsulated in $100 \mu \mathrm{m}$ drops. Bulk and

200 drop infections were incubated at $37^{\circ} \mathrm{C}$ with $95 \%$ relative humidity and $5 \% \mathrm{CO}_{2}$, and frozen at $20120^{\circ} \mathrm{C}$ at 0 and $24 \mathrm{~h}$ post infection (hpi).

\subsection{IAV infection of suspension Siat7e cells}

204 To infect the Siat7e suspension cells at an MOI of $0.1,1 \times 10^{7}$ cells were pelleted at $500 \times \mathrm{g}$ for

$2055 \mathrm{~min}$ in a $50 \mathrm{~mL}$ conical centrifuge tube then resuspended in $200 \mu \mathrm{L}$ of virus inoculum in

206 DMEM supplemented with $1 \mathrm{mM}$ HEPES (HyClone), 1X Penicillin/Streptomycin (Fisher

207 Scientific), 0.1\% Bovine Serum Albumin (BSA) (MP Biomedical) and $1 \mu \mathrm{g} / \mathrm{ml}$ of TPCK-trypsin

208 (Weingartl et al., 2010). The $50 \mathrm{~mL}$ tube containing the cells and virus inoculum was shaken at

$20990 \mathrm{rpm}$ for $1 \mathrm{~h}$. The cells were pelleted at $500 \times \mathrm{g}$ for $5 \mathrm{~min}$ and the inoculum was removed and

210 replaced with fresh DMEM infection media $(10 \mathrm{~mL})$ for bulk infections or DMEM encapsulation

211 media as described in 2.6. Infected cells were either encapsulated in $100 \mu \mathrm{m}$ drops, or replated as

212 a bulk control. For bulk infections, a 1-mL volume of cells was added to each well of a 6-well

213 plate (2 total) and placed on the shaker. Encapsulated cells were processed as described in 2.3.

214 Bulk and drop infections were incubated at $37^{\circ} \mathrm{C}$ with $95 \%$ relative humidity and $5 \% \mathrm{CO}_{2}$, and

215 frozen at $-20^{\circ} \mathrm{C}$ at 0 and 24 hpi. 


\subsection{M gene abundance by RT-qPCR}

218 RNA was extracted from cell suspensions using the QIAGEN QIAmp viral RNA mini kit. RNA

219 copy number of the IAV Matrix protein gene (M gene) was determined using a Taqman RT-

220 qPCR assay (Loveday et al., 2021). Amplification primer sequence was originally described by

221 Shu et al (Shu et al., 2011): M gene Forward 5'- GACCRATCCTGTCACCTCTGAC-3', M

222 gene Reverse 5'- AGGGCATTCTGGACAAATCGTCTA-3'. The sequence of M gene Taqman

223 probe was: 5'-/FAM/ TGCAGTCCTCGCTCACTGGGCACG/BHQ1/-3'. Working stocks of the

224 primers and probe (Eurofins Operon) were prepared at $25 \mu \mathrm{M}$ and $10 \mu \mathrm{M}$, respectively, for use

225 in the RT-qPCR reaction. Samples were amplified using a SuperScript III Platinum One-Step

226 RT-qPCR kit (Invitrogen 11732-020) with a final reaction volume of $25 \mu 1$. Each reaction mix

227 contained $400 \mathrm{nM}$ M gene Forward and Reverse primers, $200 \mathrm{nM}$ M gene Taqman probe, 0.05

$228 \mu \mathrm{M}$ ROX reference dye, $5 \mathrm{U} / \mu \mathrm{l}$ SUPERase RNase Inhibitor (Invitrogen AM2694), and $2.5 \mu 1$ of

229 RNA template. Thermocycling was performed in a RT-qPCR machine (Quantstudio 3, Applied

230 Biosystems) with the following cycling conditions: 1 cycle for $30 \mathrm{~min}$ at $60^{\circ} \mathrm{C}, 1$ cycle for $2 \mathrm{~min}$ 231 at $95^{\circ} \mathrm{C}$, and 40 cycles between $15 \mathrm{sec}$ at $95^{\circ} \mathrm{C}$ and $1 \mathrm{~min}$ at $60^{\circ} \mathrm{C}$.

\subsection{Plaque Assay}

234 Post-infection IAV titers were determined by plaque assay on MDCK cells seeded in 6-well

235 plates at $1 \times 10^{6}$ cells per well. Viral supernatant sampled from infected cells at 0 and 24 hpi was 236 serially diluted in DMEM media with $1 \mathrm{mM}$ HEPES (HyClone), 1X Penicillin/Streptomycin

237 (Fisher Scientific), 0.1\% BSA and $2 \mu \mathrm{g} / \mathrm{ml}$ of TPCK-trypsin (Worthington Biomedical). Overlay 238 media consisting of 2X MEM with 2X Penicillin/Streptomycin, 1mM HEPES, $2 \mu \mathrm{g} / \mathrm{ml}$ of TPCK 239 and 3\% Carboxy Methyl Cellulose (MP Biomedical) with $0.2 \mathrm{mg} / \mathrm{mL}$ DEAE-dextran (MP

240 Biomedical) was added and well plates were incubated at $37^{\circ} \mathrm{C}$ for 4 days. Plaques were fixed

241 with $10 \%$ buffered formalin (Fisher), washed with DI water, and stained with $0.5 \%$ crystal violet 242 (Thermo Fisher Scientific) for visualization. 


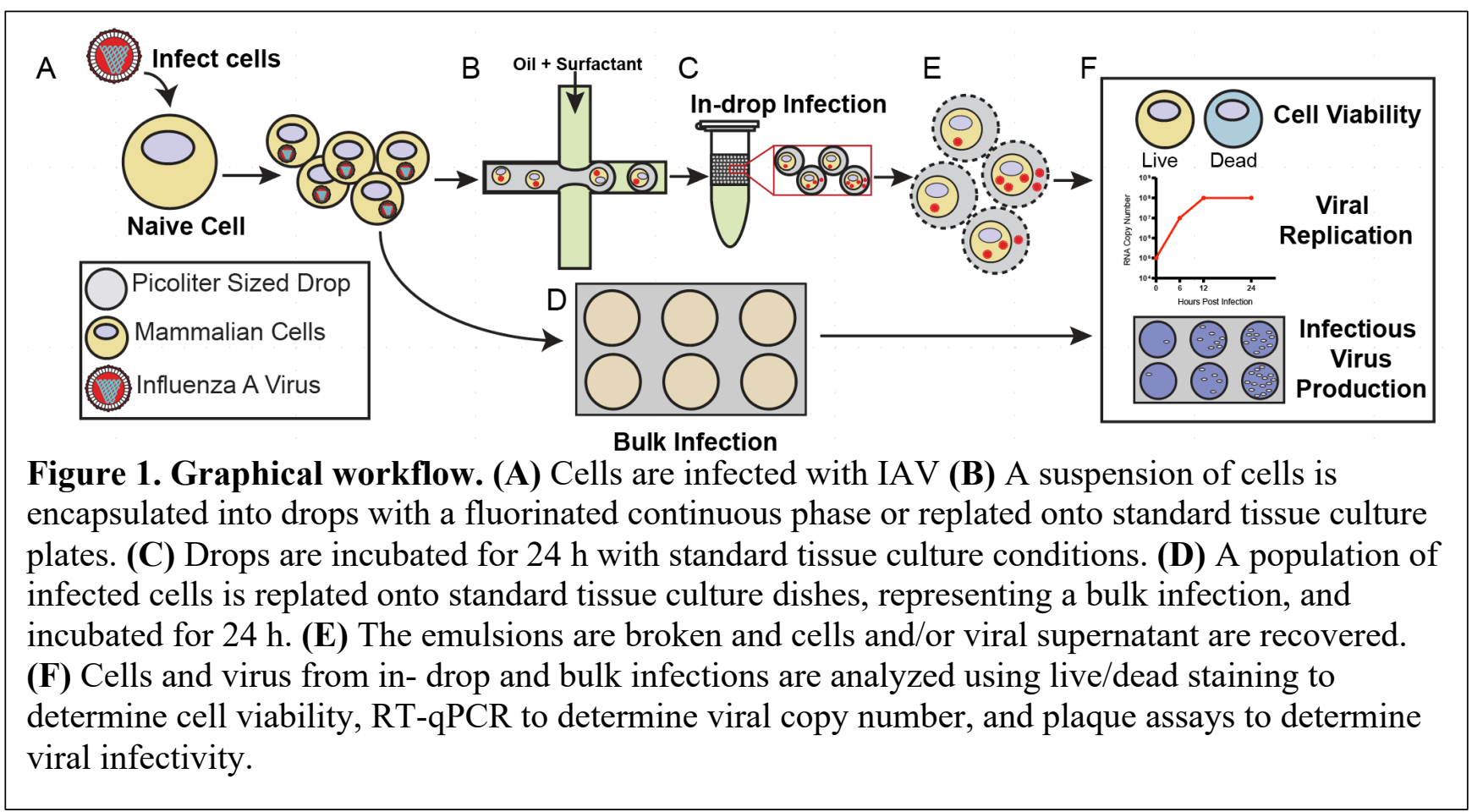
infection workflow to compare drops to bulk is outlined in Fig 1. Naïve cells were infected with IAV at an MOI of 0.1 prior to encapsulation such that most cells were infected with a single infectious virus particle (Fig. 1A). Following inoculation, cells were dissociated from the tissue 252 culture plates and processed for encapsulation into $100 \mu \mathrm{m}$ drops and bulk samples were replated 253 while the remaining cells were encapsulated as aqueous drops (Fig. 1B). Both encapsulated and 254 bulk cells were processed similarly to ensure that trypsinization from the tissue culture plates and 255 subsequent centrifugation and washing did not interfere with infection kinetics. A “ 0 ” $\mathrm{h}$ bulk and 256 drop sample was obtained immediately following replating or encapsulation. The remaining bulk 257 and drop samples were incubated for $24 \mathrm{~h}$ at $37^{\circ} \mathrm{C}$ to allow for a minimum of one round of virus 258 replication (Fig. 1C and D). At 24 hpi, viral supernatant was collected from both the bulk and 259 drop samples for analysis of virus replication and production via qRT-PCR and plaque assays, 260 respectively. To sample viral supernatant from encapsulated infections, the drops were placed in 261 the freezer and, upon thawing, treated with 20\% PFO in HFE7500 to break the emulsions and 262 release the cells and viral supernatant for collection (Fig. 1E). We compared cell viability, viral 
replication and infectious virus production from cells maintained in bulk culture and from cells encapsulated in drops (Fig. 1F).
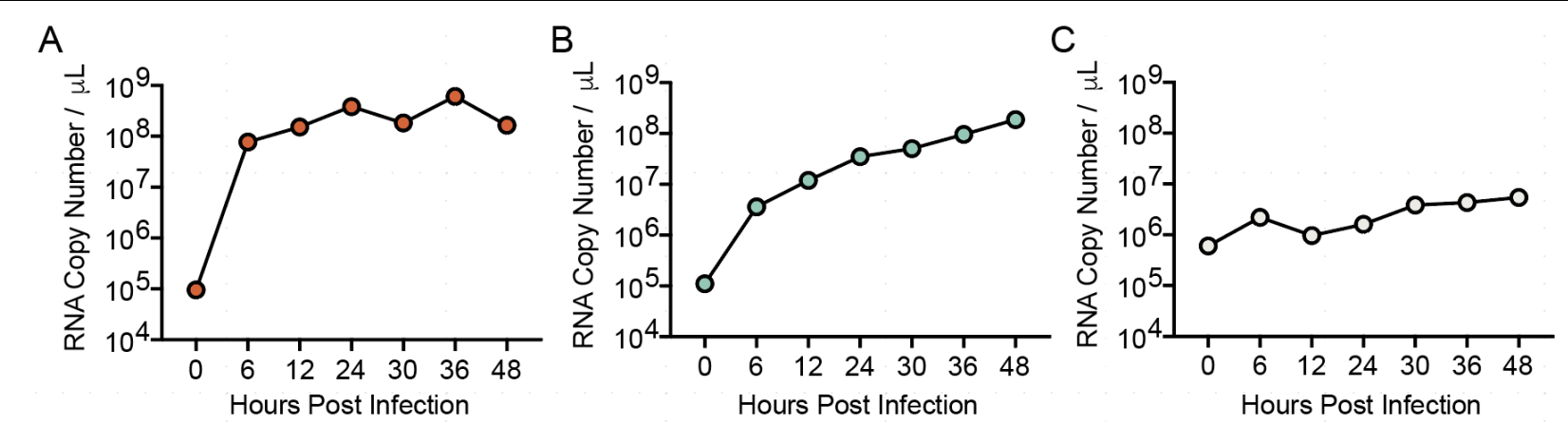

Figure 2. IAV infection in different cell lines. IAV replication, as measured by RT-qPCR over 48 hpi in (A) A549, (B) MDCK, and (C) Siat7e cells. All data represents the mean \pm SD of a minimum of two independent replicates. Error bars are present.

\subsection{Validating IAV infection in different cell lines}

Before performing IAV infection in drops, IAV viral replication was studied in bulk using three different cell lines: A549, MDCK, and Siat7e cells. Both the A549 and MDCK cells are anchorage dependent and are commonly used to propagate IAV and investigate various aspects of viral infection. Siat7e cells are a modified MDCK cells line that can grow in suspension and were developed to simplify cell culture-based IAV vaccine production (Chu et al., 2009; Chu et al., 2010). The Siat7e cells are anchorage independent and were tested for their potentially more favorable compatibility to drop encapsulation (Fischer et al., 2015; Tao et al., 2015a). IAV replication was compared between the different cell lines to determine the baseline kinetics of viral infection in a bulk infection. The cells were infected at an MOI of 0.1 and viral RNA abundance were measured at 0, 6, 12, 24, 30, 36 and 48 hpi (Fig. 2A-C). A549 cells demonstrated the most robust viral RNA replication during infection with $9.5 \times 10^{4}$ genome copies/ $\mu \mathrm{L}$ at $0 \mathrm{hpi}$, which increased to $3.9 \times 10^{8}$ genome copies/ $\mu \mathrm{L}$ at $24 \mathrm{hpi}$, a 1000 -fold increase. Between 24 and 48 hpi, the amount of RNA detected fluctuated slightly but remained between 1.6 and $6.1 \times 10^{8}$ genome copies $/ \mu \mathrm{L}$. MDCK cells demonstrated a slower increase in

282 viral replication with $1.1 \times 10^{5}$ genome copies/ $\mu \mathrm{L}$ at $0 \mathrm{hpi}$, increasing to $3.5 \times 10^{7}$ genome 283 copies/ $\mu \mathrm{L}$ at $24 \mathrm{hpi}$, a 100-fold increase, before reaching $1.9 \times 10^{8}$ genome copies/ $\mu \mathrm{L}$ at 48 hpi. 

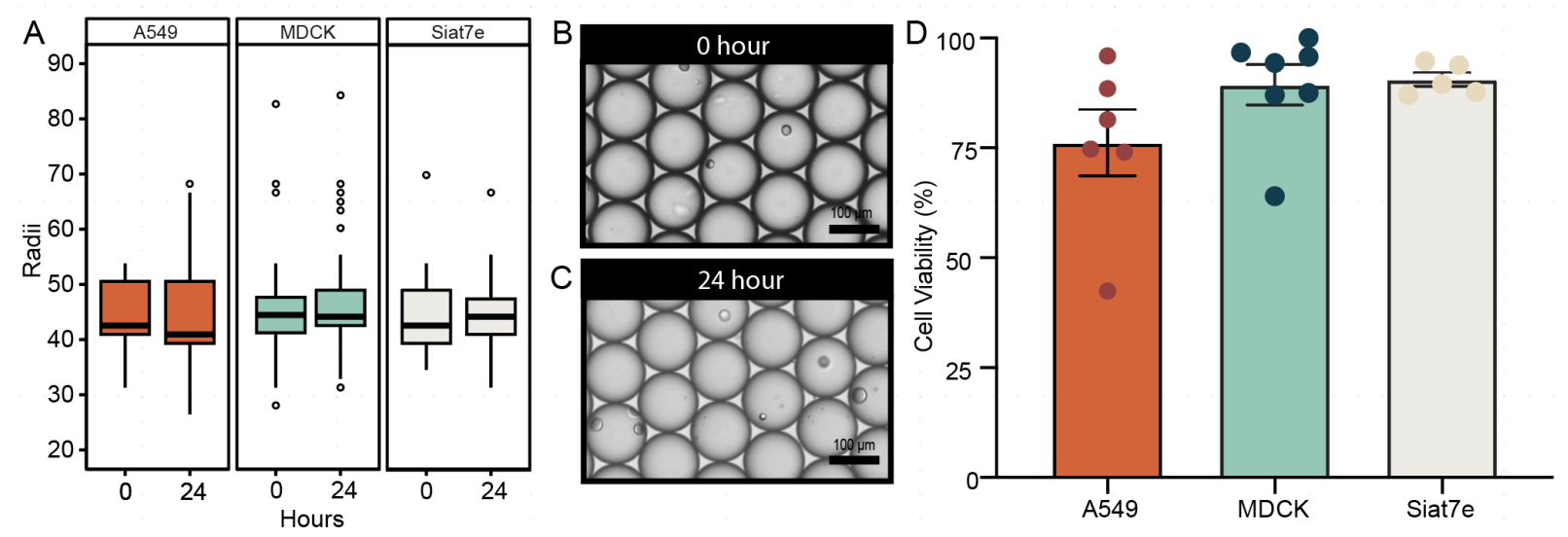

Figure 3. Drop stability and cell viability in $\mathbf{1 0 0} \boldsymbol{\mu m}$ microfluidic drops. (A) Drop radii of encapsulated A549 $(n=4,067), \operatorname{MDCK}(n=4,235)$, and Siat7e $(n=3,858)$ at 0 and $24 \mathrm{~h}$. (B) Representative images of A549 cells encapsulated in drops at $0 \mathrm{~h}$ and (C) $24 \mathrm{~h}$. Scale bars are $100 \mu \mathrm{m}$. (D) A549, MDCK, and Siat7e cell viability at $24 \mathrm{~h}$ post-encapsulation as represented by the mean \pm SEM.

hpi, with $6.0 \times 10^{5}$ genome copies/ $\mu \mathrm{L}$ at 0 hpi and $5.4 \times 10^{6}$ genome copies/ $\mu$ Lat 48 hpi. The average genomes $\mu \mathrm{L}$ for A549, MDCK, and Siat7e cells from 6-48 hpi, the time frame that represents active IAV replication where the $0 \mathrm{~h}$ measurement represents the inoculating dose, was $2.6 \times 10^{8}, 6.4 \times 10^{7}$, and $2.9 \times 10^{6}$, respectively, demonstrating cell type dependent

\subsection{Drop stability and cell viability during incubation}

292 Studying viral infection of individual cells within microfluidic drops requires that drops resist coalescence following cell encapsulation and incubation. Cell encapsulation and incubation in different medias can change the aqueous chemistry of microfluidic drops, and increases in salt concentrations or temperature $\left(37^{\circ} \mathrm{C}\right.$ overnight) can disrupt drop stability (Etienne, Kessler, and Amstad, 2017). The A549, MDCK and Siat7e cells were encapsulated in $100 \mu \mathrm{m}$ drops and incubated at $37^{\circ} \mathrm{C} / 5 \% \mathrm{CO} 2$ incubator for $24 \mathrm{~h}$. The distribution of drop radii $(R)$ between 0 and $24 \mathrm{~h}$ was used to quantify drop stability following encapsulation and incubation of all three cell lines (Fig 3A). The average $R$ at $0 \mathrm{~h}$ for A549 cells was $45.1 \mu \mathrm{m}$ with a $95 \%$ confidence interval (CI) of $[35.9,54.3]$ which decreased by $0.9 \mu \mathrm{m}$ with a $95 \%$ CI of $[0.99,0.75] \mu \mathrm{m}$ after incubation for $24 \mathrm{~h}$. For MDCK cells the average $R$ at $0 \mathrm{~h}$ was $44.6 \mu \mathrm{m}$, with a $95 \%$ CI of [35.3, 53.9] $\mu \mathrm{m}$, which increased by $1.32 \mu \mathrm{m}$ with a 95\% CI of $[1.15,1.49] \mu \mathrm{m}$ after incubation for 24

$303 \mathrm{~h}$. For the Siat7e cells the average $R$ at $0 \mathrm{~h}$ was $44.8 \mu \mathrm{m}$ with a $95 \%$ CI of $[35.5,54.2] \mu \mathrm{m}$, and

304 similar to MDCK cells this increased by $0.7 \mu \mathrm{m}$ with a $95 \%$ CI of $[0.57,0.91] \mu \mathrm{m}$ after 
305 incubation for $24 \mathrm{~h}$. A linear mixed effects model, with the experimental date as a random

306 factor, was used to determine if there was a significant change in drop $R$ and if this change is a

307 function of the cell type or timepoint post encapsulation. The change in drop $R$ from 0 to $24 \mathrm{~h}$

308 following encapsulation of either A549 or MDCK cells was considered significantly different (p-

309 value $=<0.001$ for both) while the change in drop $R$ from encapsulated Siat7e cells was not

310 significant $(\mathrm{p}$-value $=0.323)$. However, given the small changes in drop $R$ compared to the drop

311 size and the changes in drop size being less than the camera resolution of $1.6 \mu \mathrm{m} / \mathrm{pixel}$, these

312 data indicated that cell incubation does not have a meaningful impact on changes in drop

313 stability, as measured by changes in drop $R$. Representative images of encapsulated A549 cells at

$3140 \mathrm{~h}$ (Fig 3B) and $24 \mathrm{~h}$ (Fig 3C) further demonstrates drop stability.

315 To assess cell viability, drops containing cells were broken after 24 hours of incubation

316 and the aqueous layer which contained the cells was collected and analyzed with a colorimetric

317 cell viability stain. Each of the three cell lines showed cell viability over $75 \%$. Average live cell

318 viability percentages were $76.2 \pm 7.6 \%$ for A549 cells, $89.3 \pm 4.6 \%$ for MDCK cells, and $90.6 \pm$

$3193.5 \%$ for Siat7e cells. The high cell viability observed in the Siat7e cells was expected as they

320 are non-adherent so there are no physiological changes when encapsulated within drops. For the

321 adherent cell lines, viability of the MDCK cells was similar to the Siat7e. While viability of the

322 A549 cells was less than that observed in the MDCK and Siat7e cells in drops, there was not a

323 significant difference. We hypothesize that the differences observed in viability between the

324 adherent A549 and MDCK cells was due to inherent differences between the cells themselves.

325 MDCK cells are more prone to overgrowing and detaching from tissue culture flasks and do not

326 display strong contact inhibition and therefore may be slightly better suited for drop

327 encapsulation. In comparison, A549 cells demonstrate strong contact inhibition and rarely detach

328 from tissue culture flasks. These inherent differences may impact cell viability following

329 encapsulation into microfluidic drops. 


\section{1}

332

333

334

335

336

337

338

339

340

341

342

343

344

345

346

347

348

349

350

351

352

353

354

355

\subsection{Cell loading in microfluidic drops}

The majority of drops should contain one cell in single cell studies. The number of cells loaded into drops can be estimated using a Poisson distribution when the concentration of cells is known and the cells do not interact with each other during encapsulation (Collins et al., 2015). Thus, the average number of cells per drop $(\lambda)$ can be estimated using the starting cell concentration and the drop volume (Mazutis et al., 2013).

Loading cells at a density of $2 \times 10^{6}$ cells $/ \mathrm{mL}$ into $100 \mu \mathrm{m}$ drops should result in a $\lambda$ of 1.0 and result in $37 \%$ of drops containing no cells, $37 \%$ of drops containing one cell, $18 \%$ of drops containing two cells, $6 \%$ of drops containing three cells, and $1.9 \%$ of drops containing four or more cells (Poisson statistics). All three cell lines were therefore loaded at a density of $2 \times 10^{6}$ cells $/ \mathrm{mL}$ and analyzed to determine if they followed a $\lambda$ of 1 . Cell counts were completed using high-speed video footage at the microfluidic device flowfocusing junction as well as still images of drops loaded onto a hemocytometer (Fig 4A and 4B). A549 cells had $10.8 \pm 1.9 \%$ and $13.1 \pm 3.6 \%$ of drops containing one cell on the hemocytometer

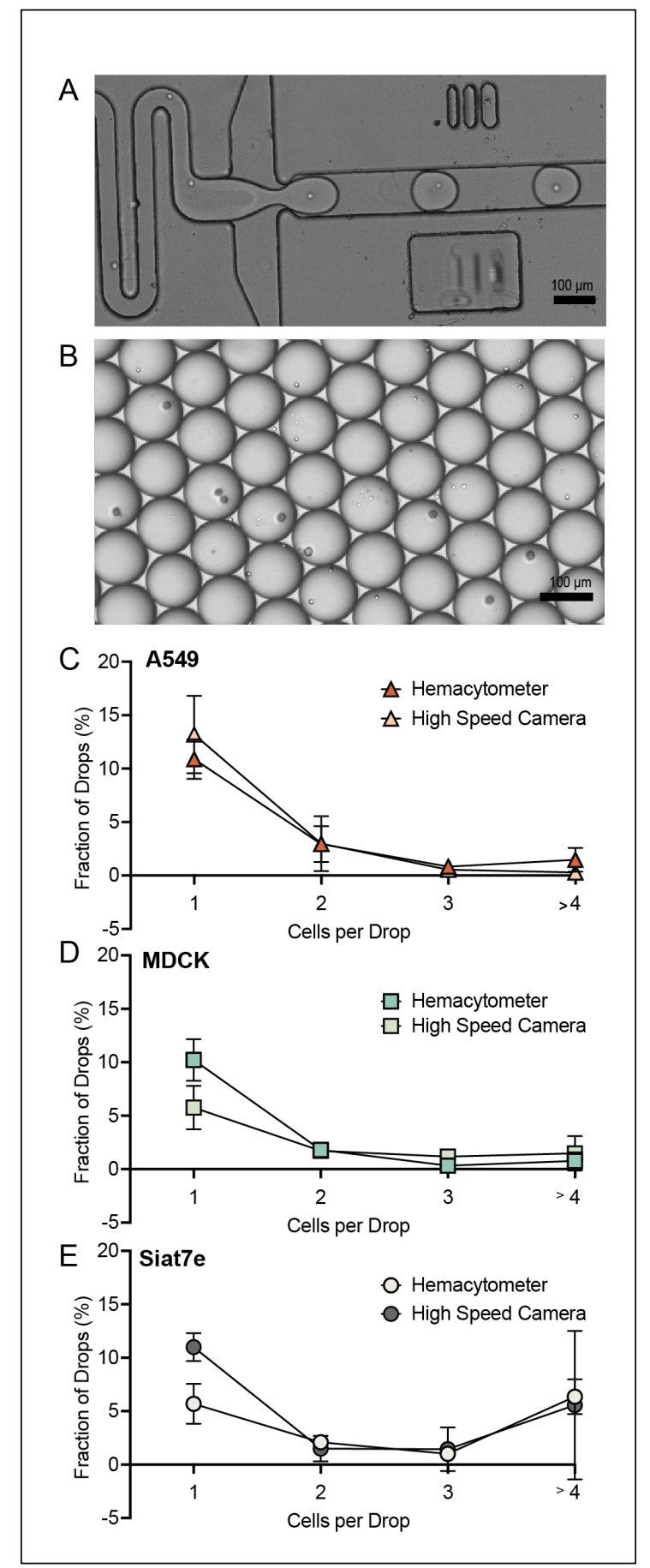

Figure 4: Cell encapsulation in microfluidic drops. (A) Still image of high-speed camera footage during cell encapsulation. (B) Representative image of drops encapsulated onto a hemocytometer. (C) A549 cell loading as measured with the hemocytometer (red triangle, $\mathrm{n}=600$ ) and high-speed camera (peach triangle, $\mathrm{n}=405$ ) (D) MDCK cell loading as measured with the hemocytometer (aqua square, $\mathrm{n}=601$ ) and high-speed camera (green square, $n=393$ ) (E) Siat7e cell loading as measured with the hemocytometer (light grey circle, $\mathrm{n}=598$ ) and high-speed camera (dark grey circle, $\mathrm{n}=431$ ). All scale bars are $100 \mu \mathrm{m}$.

356 and high-speed camera, respectively (Fig 4C). MDCK cells had 10.2 $\pm 1.9 \%$ and $5.8 \pm 2.0 \%$ of

357 drops containing one cell on the hemocytometer and high-speed camera, respectively (Fig 4D). 
358 Siat 7 e cells had $5.7 \pm 1.9 \%$ and $11.0 \pm 1.3 \%$ of drops containing one cell on the hemocytometer 359 and high-speed camera, respectively (Fig 4E).

360 The calculated $\lambda$ was used to compare the cell loading across the three cell lines and the 361 two imaging methods to the theoretical Poisson distribution. The calculated $\lambda$ ranged from 0.021 362 to 0.14 , which corresponds to a theoretical Poisson distribution for a lower starting cell 363 concentration of $3 \times 10^{5}$ cells $/ \mathrm{mL}$. We hypothesize that this discrepancy was most likely due to 364 cell settling in the syringe during loading and cell adherence to the filter upstream of the flow365 focusing junction. However, the calculated $\lambda$ depended on the measurement method and cell line 366 being evaluated. For A549 cells, the $\lambda$ was 0.021 with a 95\% CI of $[0.01,0.043]$ when measured 367 with the high-speed camera and was 0.041 with a $95 \%$ CI of $[0.012,0.126]$ when measured with 368 a hemocytometer $(\mathrm{p}$-value $=0.025)$. The $\lambda$ for the Siat7e cells measured with the high-speed 369 camera was 0.141 with a $95 \%$ CI of [0.044, 0.427] while the measurements on the same dates 370 with a hemocytometer had a $\lambda$ of 0.085 with a $95 \%$ CI of $[0.027,0.263]$ (p-value $=0.017)$. The 371 drops containing the Siat7e cells had the widest 95\% CI. These results show a significant 372 difference in the measured cell loading for A549 cells and Siat7e cells as determined with the 373 high-speed camera and the hemocytometer ( $\mathrm{p}$-values $<0.001$ ). In contrast, the $\lambda$ for MDCK cells 374 was 0.019 with a $95 \%$ CI of $[0.006,0.066]$ when measured with the high-speed camera and was 3750.025 with a $95 \%$ CI of $[0.007,0.085]$ when measured with a hemocytometer. This was not 376 considered a significant difference $(\mathrm{p}$-value $=0.942)$ suggesting that the two methods used for 377 MDCK cells were comparable for determining cell loading.

378 Overall, the Siat7e cells demonstrated the greatest variability and unpredictability in cell 379 loading across both methods. We hypothesize that this is due to the cells adhering together, 380 which is also visible during normal cell growth in a shaker flask, in which large clumps of cells 381 arise during growth. Due to poor cell encapsulation and low IAV replication during infection, 382 Siat7e cells were excluded from further analysis. 

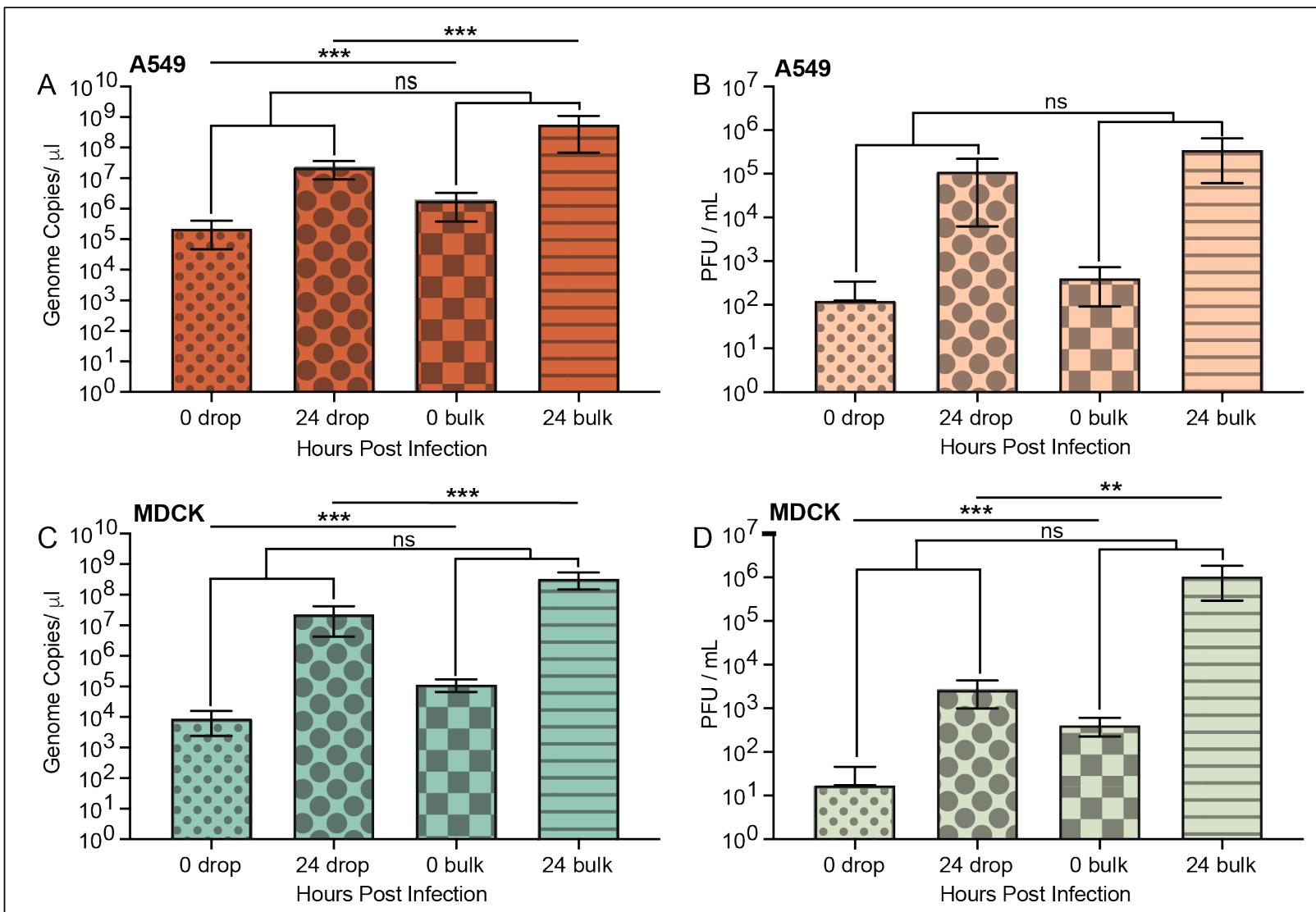

Figure 5: Comparison of in drop and bulk IAV infections in A549 and MDCK cells. (A) RNA copy number of A/Cal/07/2009 H1N1 IAV in A549 cells infected at an MOI of 0.1 at 0 hpi in drops (red small dots), 24 hpi in drops (red large dots), 0 hpi in bulk (red squares), and $24 \mathrm{hpi}$ in bulk (red stripe). (B) Infectious virions (PFU/mL) released from A549 cells at 0 hpi in drops (peach small dots), 24 hpi in drops (peach large dots), 0 hpi in bulk (peach squares), and 24 hpi in bulk (peach stripe). (C) RNA copy number of A/Cal/07/2009 H1N1 IAV in MDCK cells infected at an MOI of 0.1 at $0 \mathrm{hpi}$ in drops (aqua small dots), $24 \mathrm{hpi}$ in drops (aqua large dots), 0 hpi in bulk (aqua squares), and $24 \mathrm{hpi}$ in bulk (aqua stripe). (D) Infectious virions (PFU/mL) released from MDCK cells 0 hpi in drops (green small dots), 24 hpi in drops (green large dots), 0 hpi in bulk (green squares), and 24 hpi in bulk (green stripe). All data represented as the mean \pm the $\mathrm{SD}$ with a minimum of three independent experiments.

\subsection{IAV propagation in microfluidic drops}

Following analysis of cell encapsulation and viability of A549 and MDCK cells, IAV propagation was compared between A549 and MDCK cells in bulk and in drops. A549 and MDCK cells were infected at an MOI of 0.1 with the A/California/07/2009 H1N1 IAV strain.

Viral RNA, measured using RT-qPCR, and infectious virus output, determined by plaque assays, from cells in drops and cells incubated in bulk on standard tissue culture plates at 0 and 24 hpi allowed us to quantify the increase in virus replication and infectious virus output for both bulk and drop infections. For A549 cells, the number of genome copies/ $\mu \mathrm{L}$ in drops, as measured by 
391 M gene RNA copy number using RT-qPCR, was $2.3 \times 10^{5}$ genome copies $/ \mu \mathrm{L}$ at $0 \mathrm{~h}$ and 392 increased to $2.3 \times 10^{7}$ genome copies/ $\mu \mathrm{L}$ at $24 \mathrm{~h}$ (Fig 5A). Bulk infections of A549 cells had a 393 comparable increase with $1.8 \times 10^{6}$ genome copies at $0 \mathrm{~h}$ and $5.6 \times 10^{8}$ genome copies $/ \mu \mathrm{L}$ at 24

$394 \mathrm{~h}$ (Fig 5A). The $\log$ RNA concentration in drops compared to bulk at $0 \mathrm{~h}$ and at $24 \mathrm{~h}$ were

395 significantly different (p-value 0.0006 and 4.3E-09, respectively) which we hypothesize is due to 396 a lower number of cells associated with the in-drop samples due to calculated cell encapsulation.

397 However, the log difference of RNA produced by cells from 0 to $24 \mathrm{~h}$ in drops compared to cells 398 in bulk was not significant (p-value 0.057) and suggests that viral replication was not impacted 399 by cell encapsulation in drops. Recovery of infectious virus from A549 cells over the same $24 \mathrm{~h}$ 400 incubation period was also consistent between IAV infection in drops and bulk culture with $1.1 \times$ $40110^{5} \mathrm{PFU} / \mathrm{mL}$ and $3.6 \times 10^{5} \mathrm{PFU} / \mathrm{mL}$ recovered at $24 \mathrm{hpi}$, respectively (Fig $5 \mathrm{~B}$ ). Surprisingly, the $402 \log \mathrm{PFU} / \mathrm{mL}$ concentration in drops compared to bulk at $0 \mathrm{~h}$ and at $24 \mathrm{~h}$ was not significantly 403 different (p-value 0.31 and 0.71 , respectively). In addition, the amount of infectious virus 404 produced from 0 to $24 \mathrm{~h}$ in both drop and bulk infections was also not significantly different (p405 value 0.84 ). The genome to PFU ratio results in 1 PFU per $2.97 \times 10^{2}$ genomes for A549 cells in 406 drops and 1 PFU per $1.63 \times 10^{3}$ genomes in bulk, suggesting that any significant difference in 407 RNA concentration is not impacting the amount of virus being produced by A549 cells in drops.

For MDCK cells, the number of genome copies in drops was $8.9 \times 10^{3}$ genome copies $/ \mu \mathrm{L}$ 409 at $0 \mathrm{~h}$ and increased to $2.3 \times 10^{7}$ genome copies/ $\mu \mathrm{L}$ at $24 \mathrm{~h}$. Whereas, bulk infections of MDCK 410 cells increased from $1.2 \times 10^{5}$ genome copies $/ \mu \mathrm{L}$ at $0 \mathrm{~h}$ and $3.4 \times 10^{8}$ genome copies $/ \mu \mathrm{L}$ at $24 \mathrm{~h}$ 411 (Fig 5C). Similar to A549 cells, the log RNA concentrations measured in MDCK cells in drops 412 compared to bulk at $0 \mathrm{~h}$ and at $24 \mathrm{~h}$ were significantly different (p-value 7.2E-05 and 0.0002, 413 respectively) while the overall log difference of RNA produced by cells from 0 to $24 \mathrm{~h}$ was not 414 significantly different (p-value 0.6) between in drop and bulk infection. Recovery of infectious 415 virus from MDCK cells over $24 \mathrm{~h}$ in drops was $2.6 \times 10^{3} \mathrm{PFU} / \mathrm{mL}$ while bulk infections 416 produced $1.0 \times 10^{6} \mathrm{PFU} / \mathrm{mL}$ (Fig 5D). In contrast to A549 cells, the $\log \mathrm{PFU} / \mathrm{mL}$ concentrations 417 measured in MDCK cells in drops compared to bulk at $0 \mathrm{~h}$ and at $24 \mathrm{~h}$ were significantly 418 different (p-value 0.0004 and 0.003 , respectively), however this did not translate into a 419 significant difference in the change in $\log \mathrm{PFU} / \mathrm{mL}$ concentration from 0 to $24 \mathrm{~h}$ between in drop 420 and bulk infections. The genome to PFU ratio for MDCK cells was 1 PFU per $5.81 \times 10^{3}$ 421 genomes in drops and 1 PFU per $3.24 \times 10^{2}$ genomes in bulk. The low PFU to genome ratio in 
422 MDCK cells in drops could be the result of less virus being assembled compared to bulk culture

423 whereas RNA replication appears to not be impacted by encapsulation.

\section{Discussion}

Microfluidics and single cell sequencing are expanding the field of single cell virology

427 and enabling higher resolution analysis of the effects of cellular heterogeneity on viral infection

428 dynamics. Recent studies in single cell virology include the kinetics of viral production

429 (Akpinar, Timm, and Yin, 2016; Guo et al., 2017; Timm and Yin, 2012; Zhu, Yongky, and Yin,

430 2009), the distribution of viral burst size (Schulte and Andino, 2014), and characterization of

431 genetic variability using single cell-RNA sequencing (Drayman et al., 2019; Russell et al., 2019;

432 Russell et al., 2018). To understand how viral and/or cellular heterogeneity impacts the outcomes

433 of viral infection at a single cell level requires the ability to interrogate large populations of

434 individually infected cells. Many of the current studies depend upon diluting populations of cells

435 into standard well-plates to assess single cells, isolation of individual cells by FACS, or isolating

436 cells in microfluidic chambers (Guo et al., 2017). However, analyses in well-plates is typically is

437 limited to hundreds of single cells, while 2D microfluidic devices are limited to a few thousand

438 cells (Combe et al., 2015; Guo et al., 2017; Heldt et al., 2015; Kupke et al., 2020). To process

439 tens of thousands or up to millions of single cells, a continuous flow technique such as FACS or

440 drop-based microfluidics is necessary for much higher throughput, thousands of cells per second

441 (Drayman et al., 2019; Sun et al., 2020). One drawback in isolating infected cells by FACS is it

442 requires the use of antibodies to label infected cells or fluorescent markers encoded within the

443 virus itself, which may not be accurate in highly heterogenous populations. FACS sorting can

444 also be limited to early timepoints post infection to ensure that virus spread is reduced, and

445 infection parameters are similar so that data is comparable from cell to cell. FACS analysis of

446 infected cells at early time points limits the ability to investigate heterogeneity at later time

447 points post infection and an inability to explore virus production. In comparison, drop-based

448 microfluidics can be used to compartmentalize individual cells within drops, thereby creating up

449 to millions of tiny bioreactors for further downstream analysis (Rotem et al., 2018; Tao et al.,

450 2015a). These compartmentalized cells in drops allow for viral infection to proceed without virus

451 spread to neighboring drops, providing a way to analyze how infection proceeds at a multitude of

452 time points and the ability to analyze virus replication, production and cellular responses at a 
453 single cell level. To date, drop-based viral infections have only been performed with MNV-1

454 using cell lines adapted to spinner cultures or already grown in suspension (Fischer et al., 2015;

455 Tao et al., 2015a; Tao et al., 2015b). The use of spinner or suspension-based cell lines for drop-

456 based microfluidics limits the applicability of the technology for studying viral infections that

457 predominantly occur in adherent cell culture-based models. In addition, studying viral infections

458 within drops has not been extended to include the plethora of eukaryotic viruses that exist and

459 impact our daily lives. The ability to expand drop-based microfluidics to include a range of

460 different cell lines and viruses would allow for more in-depth analysis of viral infection with

461 single cell resolution. Our approach evaluated the ability of standard cell lines to propagate IAV

462 infection at a single cell level using drop-based microfluidics.

463 We found that $100 \mu \mathrm{m}$ drops loaded with the A549, MDCK or Siat7e cells remained

464 stable following overnight incubation and cell viability remained high. High cell viability was

465 expected from the Siat7e cells as they are grown in shaker flasks in suspension. The high cell

466 viability from the A549 and MDCK cells, while more variable between experiments than the

467 Siat7e cells, was also promising as both cell lines are adherent cell lines traditionally grown on

468 tissue culture flasks and vessels. Previous studies exploring viability of cells in drops found that

469 smaller drop sizes resulted in low levels of cell viability, even after a couple of hours, most likely

470 due to lack of enough nutrients or buildup of waste products within the drop (Köster et al., 2008).

471 Our data demonstrates that drop-based microfluidics can be used to encapsulate and incubate a

472 wider range of cell types for single cell analysis. While we only analyzed cells over a $24 \mathrm{~h}$ time

473 span to accommodate the lifecycle of IAV, we expect that incubation of encapsulated cells for

474 longer periods is possible.

475 The majority of drops with cells contained 1 cell per drop after loading. Using a Poisson

476 distribution to model the expected cell loading based on cell concentration and drop size, we

477 determined that a $\lambda$ of 1 , in which the majority of drops contained 1 cell, was represented by a

478 cell concentration of $2 \times 10^{6}$ cells $/ \mathrm{mL}$ for $100 \mu \mathrm{m}$ drops (50 $\mu \mathrm{m}$ radii). We also assumed that all

479 the cells in the suspension have an equal probability of encapsulation. However, throughout our

480 experiments, cells settled in the syringes and attached to the aqueous-stream filter on the

481 microfluidic drop-maker, lowering the number of cells being encapsulated. Therefore, the $\lambda$ in

482 our experiments was similar to a much lower cell concentration, although the majority of our

483 loaded drops still contained a single cell. Surprisingly, the $\lambda$ for the Siat7e cell line had the 
484 largest variation and was significantly different from the other two cell lines, with more drops

485 having with $4+$ cells/drop than was observed for the A549 or MDCK cells. We hypothesize that

486 this was due to the Siat7e cells adhering to each other when cultured in a shaker flask and

487 during infection prior to cell encapsulation. To improve cell loading, a higher concentration of

488 cells can be used, although previous analysis of 2,4 or $8 \times 10^{6}$ cells $/ \mathrm{mL}$ in $50 \mu \mathrm{m}$ drops had

489 similar loading patterns (Fischer et al., 2015). We have observed cell loading that more closely

490 follows the Poisson distribution for a given cell concentration with different cell types, such as

491 true suspension cell lines (data not shown), so it is advisable to test cell loading for any new cell

492 types being encapsulated into microfluidic drops. Furthermore, our analysis methods using

493 either a high-speed camera or low-tech hemocytometer to determine cell loading resulted in

494 significantly different $\lambda$ values, with the low-tech hemocytometer providing more consistent

495 results. This suggests that while either method can be utilized for quantifying cell loading, a

496 simple count using images taken on a hemocytometer is sufficient.

$497 \quad$ Following our success in encapsulation and culturing multiple cell lines within

498 microfluidic drops, we investigated whether infected cells would continue to produce virus

499 following encapsulation. We explored the ability of A549 and MDCK cells only due to highly

500 variable cell loading and low virus production from the Siat7e cells. Viral RNA and titers were

501 measured at 0 and $24 \mathrm{~h}$ post encapsulation and compared to standard bulk infections on well

502 plates. The amount of virus produced from each cell line between 0 and $24 \mathrm{~h}$ in bulk was not

503 significantly different than the amount of virus produced from cells encapsulated and incubated

504 within drops. Our data demonstrates that microfluidic drops can be used to propagate IAV from

505 individual cells and that adherent standard cell lines can be used, reducing the need for

506 development of different model systems for studying infections at a single cell level.

507 Previous analysis of virus infection in drops was performed with MNV-1, a positive

508 sense RNA virus in a small icosahedral capsid. In comparison to IAV, MNV-1 is extremely

509 stable at a range of environmental conditions and lacks an outer envelope (Henderson, 2008).

510 Here we have demonstrated that an enveloped virus with reduced environmental stability can be

511 produced from standard cell lines in drops at a similar rate to what is observed in a bulk culture,

512 which enables more extensive analysis of virus infection at a single cell level. Previous studies

513 exploring viral kinetics and replication (Holmes, Zhang, and Bieniasz, 2015; Timm and Yin,

514 2012) and innate immune activation (Russell et al., 2019; Timm et al., 2017), have provided new 
515 insight into the heterogeneity surrounding viral infections. The ability to expand single cell

516 analysis to tens of thousands of cells in a high throughput manner has the potential to

517 revolutionize virology studies.

\section{Conclusions}

Analysis of individually infected cells has revealed how complex and heterogenous viral infections are, even in controlled laboratory settings (Combe et al., 2015; Russell et al., 2019;

522 Russell et al., 2018; Sun et al., 2020). The implementation of -omics technology to these systems

523 has further demonstrated how viral infections are as complicated at a single cell level as they are

524 within a larger host or system (Prakadan et al., 2017; Xu et al., 2020; Zilionis et al., 2017). These

525 applications of new technology to the study of virology allow us to look closer at how individual

526 host cells drive viral evolution and responses to the innate and adaptive immune systems. With

527 the current COVID-19 pandemic and the emergence of multiple viral variants with populations,

528 it is critical to expand our ability to study how these variants arise, how they operate under

529 selective pressures, and how this impacts transmission and virulence moving forward (Harvey et

530 al., 2021). The ability to study these aspects in individual cells has been limited by low

531 throughput analysis, reliance on expensive cell sorting machinery, or viruses that are easily

532 manipulated to express fluorescent markers. The use of drop-based microfluidics offers the

533 ability to perform high throughput analysis of individual cells (Gérard et al., 2020; Loveday et

534 al., 2021; Matuła et al., 2020). In addition, these applications can be adapted to many

535 laboratories with minimal investment. Our approach and methods described here provide a

536 framework for pursuing single cell studies of virus infections using drop-based microfluidics.

\section{References}

Akpinar, F., Timm, A. and Yin, J., 2016. High-throughput single-cell kinetics of virus infections in the presence of defective interfering particles. Journal of virology 90, 1599-1612. in microchannels. Applied Physics Letters 82, 364-366.

Brooke, C.B., 2017. Population Diversity and Collective Interactions during Influenza Virus Infection. J Virol 91.

Chu, C., Lugovtsev, V., Golding, H., Betenbaugh, M. and Shiloach, J., 2009. Conversion of MDCK cell line to suspension culture by transfecting with human siat7e gene and its application for influenza virus production. Proc. Natl. Acad. Sci. U. S. A. 106, 1480214807. 
Chu, C., Lugovtsev, V., Lewis, A., Betenbaugh, M. and Shiloach, J., 2010. Production and antigenic properties of influenza virus from suspension MDCK-siat7e cells in a benchscale bioreactor. Vaccine 28, 7193-7201.

Collins, D.J., Neild, A., deMello, A., Liu, A.Q. and Ai, Y., 2015. The Poisson distribution and beyond: methods for microfluidic droplet production and single cell encapsulation. Lab Chip 15, 3439-59.

Combe, M., Garijo, R., Geller, R., Cuevas, J.M. and Sanjuán, R., 2015. Single-Cell Analysis of RNA Virus Infection Identifies Multiple Genetically Diverse Viral Genomes within Single Infectious Units. Cell Host Microbe 18, 424-432.

Cristinelli, S. and Ciuffi, A., 2018. The use of single-cell RNA-Seq to understand virus-host interactions. Curr. Opin. Virol. 29, 39-50.

Dolan, P.T., Whitfield, Z.J. and Andino, R., 2018. Mapping the Evolutionary Potential of RNA Viruses. Cell Host Microbe 23, 435-446.

Drayman, N., Patel, P., Vistain, L. and Tay, S., 2019. HSV-1 single-cell analysis reveals the activation of anti-viral and developmental programs in distinct sub-populations. Elife 8.

Duffy, D.C., McDonald, J.C., Schueller, O.J.A. and Whitesides, G.M., 1998. Rapid Prototyping of Microfluidic Systems in Poly(dimethylsiloxane). Analytical Chemistry 70, 4974-4984.

Etienne, G., Kessler, M. and Amstad, E., 2017. Influence of Fluorinated Surfactant Composition on the Stability of Emulsion Drops. Macromolecular Chemistry and Physics 218.

Fischer, A.E., Wu, S.K., Proescher, J.B.G., Rotem, A., Chang, C.B., Zhang, H., Tao, Y., Mehoke, T.S., Thielen, P.M., Kolawole, A.O., Smith, T.J., Wobus, C.E., Weitz, D.A., Lin, J.S., Feldman, A.B. and Wolfe, J.T., 2015. A high-throughput drop microfluidic system for virus culture and analysis. J. Virol. Methods 213, 111-117.

Gérard, A., Woolfe, A., Mottet, G., Reichen, M., Castrillon, C., Menrath, V., Ellouze, S., Poitou, A., Doineau, R., Briseno-Roa, L., Canales-Herrerias, P., Mary, P., Rose, G., Ortega, C., Delincé, M., Essono, S., Jia, B., Iannascoli, B., Richard-Le Goff, O., Kumar, R., Stewart, S.N., Pousse, Y., Shen, B., Grosselin, K., Saudemont, B., Sautel-Caillé, A., Godina, A., McNamara, S., Eyer, K., Millot, G.A., Baudry, J., England, P., Nizak, C., Jensen, A., Griffiths, A.D., Bruhns, P. and Brenan, C., 2020. High-throughput single-cell activitybased screening and sequencing of antibodies using droplet microfluidics. Nat. Biotechnol.

Guo, F., Li, S., Caglar, M.U., Mao, Z., Liu, W., Woodman, A., Arnold, J.J., Wilke, C.O., Huang, T.J. and Cameron, C.E., 2017. Single-Cell Virology: On-Chip Investigation of Viral Infection Dynamics. Cell Rep. 21, 1692-1704.

Harvey, W.T., Carabelli, A.M., Jackson, B., Gupta, R.K., Thomson, E.C., Harrison, E.M., Ludden, C., Reeve, R., Rambaut, A., Consortium, C.-G.U., Peacock, S.J. and Robertson, D.L., 2021. SARS-CoV-2 variants, spike mutations and immune escape. Nat Rev Microbiol 19, 409-424.

Heldt, F.S., Kupke, S.Y., Dorl, S., Reichl, U. and Frensing, T., 2015. Single-cell analysis and stochastic modelling unveil large cell-to-cell variability in influenza A virus infection. Nat. Commun. 6, 8938 .

Henderson, K.S., 2008. Murine norovirus, a recently discovered and highly prevalent viral agent of mice. Lab Anim (NY) 37, 314-20.

Holmes, M., Zhang, F. and Bieniasz, P.D., 2015. Single-Cell and Single-Cycle Analysis of HIV1 Replication. PLoS Pathog. 11, e1004961. 
Holtze, C., Rowat, A.C., Agresti, J.J., Hutchison, J.B., Angile, F.E., Schmitz, C.H., Koster, S., Duan, H., Humphry, K.J., Scanga, R.A., Johnson, J.S., Pisignano, D. and Weitz, D.A., 2008. Biocompatible surfactants for water-in-fluorocarbon emulsions. Lab Chip 8, 16329.

Köster, S., Angilè, F.E., Duan, H., Agresti, J.J., Wintner, A., Schmitz, C., Rowat, A.C., Merten, C.A., Pisignano, D., Griffiths, A.D. and Weitz, D.A., 2008. Drop-based microfluidic devices for encapsulation of single cells. Lab Chip 8, 1110-1115.

Kupke, S.Y., Ly, L.-H., Börno, S.T., Ruff, A., Timmermann, B., Vingron, M., Haas, S. and Reichl, U., 2020. Single-Cell Analysis Uncovers a Vast Diversity in Intracellular Viral Defective Interfering RNA Content Affecting the Large Cell-to-Cell Heterogeneity in Influenza A Virus Replication. Viruses 12.

Liao, M., Liu, Y., Yuan, J., Wen, Y., Xu, G., Zhao, J., Cheng, L., Li, J., Wang, X., Wang, F., Liu, L., Amit, I., Zhang, S. and Zhang, Z., 2020. Single-cell landscape of bronchoalveolar immune cells in patients with COVID-19. Nat. Med. 26, 842-844.

Lin, J., Jordi, C., Son, M., Van Phan, H., Drayman, N., Abasiyanik, M.F., Vistain, L., Tu, H.-L. and Tay, S., 2019. Ultra-sensitive digital quantification of proteins and mRNA in single cells. Nat. Commun. 10, 3544.

Loveday, E.K., Zath, G.K., Bikos, D.A., Jay, Z.J. and Chang, C.B., 2021. Screening of Additive Formulations Enables Off-Chip Drop Reverse Transcription Quantitative Polymerase Chain Reaction of Single Influenza A Virus Genomes. Anal Chem 93, 4365-4373.

Matuła, K., Rivello, F. and Huck, W.T.S., 2020. Single-Cell Analysis Using Droplet Microfluidics. Adv Biosyst 4, e1900188.

Mazutis, L., Gilbert, J., Ung, W.L., Weitz, D.A., Griffiths, A.D. and Heyman, J.A., 2013. Singlecell analysis and sorting using droplet-based microfluidics. Nat. Protoc. 8, 870-891.

Petrova, V.N. and Russell, C.A., 2018. The evolution of seasonal influenza viruses. Nat. Rev. Microbiol. 16, 47-60.

Prakadan, S.M., Shalek, A.K. and Weitz, D.A., 2017. Scaling by shrinking: empowering singlecell 'omics' with microfluidic devices. Nat. Rev. Genet. 18, 345-361.

Rotem, A., Serohijos, A.W., Chang, C.B., Wolfe, J.T., Fischer, A.E., Mehoke, T.S., Zhang, H., Tao, Y., Lloyd Ung, W. and Choi, J.-M., 2018. Evolution on the biophysical fitness landscape of an RNA virus. Molecular biology and evolution 35, 2390-2400.

Russell, A.B., Elshina, E., Kowalsky, J.R., te Velthuis, A.J. and Bloom, J.D., 2019. Single-cell virus sequencing of influenza infections that trigger innate immunity. Journal of virology, JVI. 00500-19.

Russell, A.B., Trapnell, C. and Bloom, J.D., 2018. Extreme heterogeneity of influenza virus infection in single cells. Elife 7.

Schulte, M.B. and Andino, R., 2014. Single-cell analysis uncovers extensive biological noise in poliovirus replication. Journal of virology 88, 6205-6212.

Sen, A., Rothenberg, M.E., Mukherjee, G., Feng, N., Kalisky, T., Nair, N., Johnstone, I.M., Clarke, M.F. and Greenberg, H.B., 2012. Innate immune response to homologous rotavirus infection in the small intestinal villous epithelium at single-cell resolution. Proc. Natl. Acad. Sci. U. S. A. 109, 20667-20672.

Shu, B., Wu, K.H., Emery, S., Villanueva, J., Johnson, R., Guthrie, E., Berman, L., Warnes, C., Barnes, N., Klimov, A. and Lindstrom, S., 2011. Design and performance of the CDC real-time reverse transcriptase PCR swine flu panel for detection of 2009 A (H1N1) pandemic influenza virus. J Clin Microbiol 49, 2614-9. 
Sun, J., Vera, J.C., Drnevich, J., Lin, Y.T., Ke, R. and Brooke, C.B., 2020. Single cell heterogeneity in influenza A virus gene expression shapes the innate antiviral response to infection. PLoS Pathog 16, e1008671.

Tao, Y., Rotem, A., Zhang, H., Chang, C.B., Basu, A., Kolawole, A.O., koehler, S., Ren, Y., Lin, J.S., Pipas, J.M., Feldman, A.B., Wobus, C. and Weitz, D.A., 2015a. Rapid, targeted and culture-free viral infectivity assay in drop-based microfluidics. Lab on a Chip.

Tao, Y., Rotem, A., Zhang, H., Cockrell, S.K., Koehler, S.A., Chang, C.B., Ung, L.W., Cantalupo, P.G., Ren, Y., Lin, J.S., Feldman, A.B., Wobus, C.E., Pipas, J.M. and Weitz, D.A., 2015b. Artifact-Free Quantification and Sequencing of Rare Recombinant Viruses by Using Drop-Based Microfluidics. Chembiochem 16, 2167-2171.

Timm, A. and Yin, J., 2012. Kinetics of virus production from single cells. Virology 424, 11-17.

Timm, A.C., Warrick, J.W. and Yin, J., 2017. Quantitative profiling of innate immune activation by viral infection in single cells. Integr. Biol. 9, 782-791.

Weingartl, H.M., Berhane, Y., Hisanaga, T., Neufeld, J., Kehler, H., Emburry-Hyatt, C., HooperMcGreevy, K., Kasloff, S., Dalman, B., Bystrom, J., Alexandersen, S., Li, Y. and Pasick, J., 2010. Genetic and pathobiologic characterization of pandemic H1N1 2009 influenza viruses from a naturally infected swine herd. Journal of virology 84, 2245-56.

Xu, X., Wang, J., Wu, L., Guo, J., Song, Y., Tian, T., Wang, W., Zhu, Z. and Yang, C., 2020. Microfluidic Single-Cell Omics Analysis. Small 16, e1903905.

Zanini, F., Pu, S.-Y., Bekerman, E., Einav, S. and Quake, S.R., 2018. Single-cell transcriptional dynamics of flavivirus infection. Elife 7.

Zhu, Y., Yongky, A. and Yin, J., 2009. Growth of an RNA virus in single cells reveals a broad fitness distribution. Virology 385, 39-46.

Zilionis, R., Nainys, J., Veres, A., Savova, V., Zemmour, D., Klein, A.M. and Mazutis, L., 2017. Single-cell barcoding and sequencing using droplet microfluidics. Nat. Protoc. 12, 44-73. 